\title{
CATALAN COLLOCATION TAU METHOD OF SOLUTION OF ORDINARY DIFFERENTIAL QUATIONS
}

M. R. ODEKUNLE

(Received 28 October, 2005; Revision Accepted 25 January, 2006)

\section{ABSTRACT}

Tau method is an economized polynomial technique for solving ordinary differential equations with smooth solutions. The tau method is modified in this paper for easy computation, accuracy and speed. The modification is based on a systematic use of 'Catalan Polynomials' in collocation tau method to approximate the solution of ordinary differential equations. The method involves direct use of 'Catalan polynomials' in the solution of ordinary differential equations without first rewriting them in terms of other known functions as commonly practiced riow. The results obtained are quite comparable with the standard collocation tau methods.

\section{KEYWORDS: Collocation tau method, ordinary differential equation.}

\subsection{INTRODUCTION}

The Lanczos tau method (Lanczos, 1938) found an extensive use in the construction of mathematical and machine tables in the 1950's; see Lanczos (1952) and Clenshaw (1962). The method requires that the coefficients and the right hand side of the differential equation be polynomials. This restriction is removed by the method of selected points (Lanczos, 1956), but the choice of Chebyshev perturbation term is lost in this method. Okunuga and Onumanyi (1986) retained the use of Chebyshev perturbation term and even extended their work to the solution of ordinary differential equations (odes) with non-polynomial coefficients.

In this work, we shall follow the approach of Okunuga and Onumanyi (1986) but using as the perturbation term what we call 'Catalan Polynomials'. Also, instead of the use of multiple choice of perturbation terms meant to overcome the problem of over-determination in the resulting algebraic system of equations encountered in collocation tau method (Okunuga and Onumanyi, 1986), one perturbation term is involved in the approach employed here. This leads to an algebraic equation in which the number of unknowns is the same as the number of equations resulting in the unique determination of the unknown terms.

\subsection{COLLOCATION TAU METHOD}

Let $y(x)$ be an unknown function that satisfies a given differential equation

$$
L y(x):=p_{0}(x)+p_{1}(x) y(x)+\ldots+p_{s}(x) y^{(s)}(x)=f(x), \quad a \leq x \leq b
$$

where $y^{(\alpha)}(x)$ stands for the derivative of order $\alpha$ of $y(x)$ and the coefficients $p,(x), \mathrm{j}=0,1, \ldots, \mathrm{s}$ are not necessarily polynomials (Lanczos, 1956). We approximate the solution of $(2.1)$ by a power series of the form

$$
y(x) \approx y_{1}(x)=a_{0}+a_{1} x+\ldots+a_{i} x^{\prime}=\sum_{n=0}^{1} a_{n} x^{n}
$$

so that (2.1) becomes

$$
p_{0}(x)+p_{1}(x) y_{1}(x)+\ldots+p_{s}(x) y_{1}^{(s)}(x)=f(x)+H_{1}(x), \quad a \leq x \leq b
$$

where $H_{i}(x)$ is the residual.

For polynomial coefficients, $p_{1}(x), j=0,1,2, \ldots, \mathrm{s}$, the residual $H_{i}(x)$ is a polynomial that is replaced by a finite sum of Chebyshev polynomials (Lanczos, 1938) involving some free tau parameters. If $p,(x)$ are non polynomials, Lanczos (1956) used

$$
H_{i}(x)=\sum_{g=1}^{s} \tau_{g} T_{i-g+1}(x)
$$

where $T_{k}(x)$ is the Chebyshev polynomial of degree $k$ defined in the interval $-1 \leq x \leq 1, \tau_{1}, \tau_{2}, \ldots, \tau_{\text {, are constants }}$ to be determined. Substitute (2.4) in (2.3) and then collocate the resulting equation at $x=z_{r}, r=1,2, \ldots, i \quad s+1$ where $z_{r}$ are the $i-s+1$ zeroes of $T_{t-s+1},-1 \leq x \leq 1$ to obtain 
$p_{0}\left(z_{1}\right) y_{1}\left(z_{r}\right)+\ldots+p,\left(z_{r}\right) y_{1}^{\prime \prime \prime}\left(z_{n}\right) z f\left(z_{1}\right)+\tau_{1} T_{1}\left(z_{1}\right)+\tau_{2} T_{1-1}\left(z_{r}\right)+\ldots+\tau_{1} T_{1,+1}\left(z_{2}\right)$

In the general interval $a \leq x \leq b,(2.4)$ can be written as (Odekunle, 1993)

$$
H(x)=\sum_{g=1}^{s} \tau_{g} T^{\cdot g+1},(x)
$$

where $T_{k}^{*}(x)$ is the shifted Chebyshev polynomial of degree $\mathrm{k}$ defined in the interval $a \leq x \leq b, \mathrm{a}$ and $\mathrm{b}$ are real numbers. Substitute (2.6) in (2.3) and collocate the resulting equation at

$$
x_{1}=j h, j=1,2, \ldots i+1, \quad h=\frac{b-a}{i+1}
$$

where $h$ is the desired step-length. Hence,

$p_{0}\left(x_{1}\right) y_{1}\left(x_{1}\right)+\ldots+p_{s}\left(x_{1}\right) y^{(s)}\left(x_{1}\right)=f\left(x_{1}\right)+\tau_{1} T_{1}^{*}\left(x_{1}\right)+\tau_{2} T_{1-1}^{\cdot}\left(x_{1}\right)+\ldots+\tau_{s} T_{1.5+1}^{\cdot}\left(x_{1}\right)$

\subsection{CATALAN POLYNOMIALS}

Among the known mathematical constants, Catalan constants are one of those studied extensively. It first appeared in the estimation of combinatorial functions as (Parker, 1984)

$$
C=\sum_{k=0}^{\infty} \frac{(-1)^{k}}{(2 k+1)^{2}}
$$

It is not known if $\mathrm{C}$ is irrational (Sloane, A006752/M4593).

The previous use of Catalan constants in differential equations involve first rewriting it in other forms such as Dirichlet beta function, Legendre chi-function, Hurwitz zeta function, polygamma function etc (Weisstein, 1999) and Riemann's zeta function (Srivastava and Miller, 1990). In this work, attempt is made to apply the constants directly in solving differential equations without necessarily first writing them in terms of any other function.

\section{Definition 1}

A series of numbers given by the equation

$$
C_{n}=\frac{1}{n}\left({ }_{n}^{2 n}\right), \quad \mathrm{n}=0.1 .2, \ldots
$$

where $\left(\begin{array}{l}n \\ m\end{array}\right)=\frac{n !}{m !(n-m) !}, \quad \mathrm{n}, \mathrm{m}=0,1,2 \ldots$

is known as Catalan numbers.

From this definition

$$
C_{0}=1, C_{1}=1, C_{2}=2, C_{3}=5, C_{4}=14, C_{5}=42, C_{6}=132 \ldots
$$

\section{Definition 2}

We define Catalan polynomial $C,(x)$ as

$$
C(x)=\sum_{i=0}\left[\left.\frac{1}{1+1}\right|^{2 \prime} \mid\right] x, \quad i=0,1,2, \ldots
$$

where $T^{1}+=\frac{j !}{k !(j \quad k) !}, \quad j, k=0,1,2, \ldots$

\subsection{MAIN TOOL}

Let the residual $H,(x)$ be defined as

$$
H_{i}(x)=\pi ;(x)
$$

where $C,(x)$ is the Catalan polynomial of order i

Substitute (4.1) in (2.3) and collocate the resulting equation at

$$
x_{i}=j h, \quad j=1,2, \ldots i+1, \quad h=\frac{b-a}{i+1}
$$

to obtain 
$p_{0}\left(x_{1}\right)+p_{1}\left(x_{1}\right) y_{1}\left(x_{1}\right)+\ldots+p_{s}\left(x_{1}\right) y_{1}^{(s)}(x)=f\left(x_{1}\right)+\tau C_{1}\left(x_{1}\right)$

Solving equation (4.3) subject to the given initial or boundary conditions will result in (i+2) system of equations in (i+2) unknowns $a_{0}, a_{1}, \ldots, a_{1}$ and $\tau$ that can now be determined uniquely.

\section{0}

\section{NUMERICAL EXAMPLES}

For our numerical experiment, we shall make use of common problems used by previous authors (Okunuga and Onumanyi, 1986; Taiwo and Onumanyi, 1990 and Omolehin, 1997) so that the performance of this technique compared with theirs can easily be numerically assessed.

Example 1: $\quad y^{\prime}(x)-x^{2} y(x)=0,0 \leq \mathrm{x} \leq 1, \quad \mathrm{y}(0)=1, \quad \mathrm{y}_{\text {exact }}(x)=e^{\frac{1}{3} x^{3}}$

We assume an approximate power series solution of the form:

$$
y_{1}(x)=\sum_{i=0}^{\prime} a, x^{\prime}
$$

so that

$$
y_{i}^{\prime}(x)=\sum_{i=0}^{\prime} j a, x^{j-1}
$$

Equation (5.2a) is then substituted in the slightly perturbed form of equation (5.1) to obtain

$$
y_{1}^{\prime}(x)-x^{2} y_{1}(x)=\pi C_{1}(x)
$$

If $i=5$ then, (This shall apply to all the problems considered.) from (3.3)

$$
C_{5}(x)=1+x+2 x^{2}+5 x^{3}+14 x^{4}+42 x^{5}
$$

Substitute $(5.2)$ in (5.3) to obtain

$$
\begin{gathered}
\left(a_{1}+2 a_{2} x+3 a_{3} x^{2}+4 a_{4} x^{3}+5 a_{5} x^{4}\right)-x^{2}\left(a_{0}+a_{1} x+a_{2} x^{2}+a_{3} x^{3}+a_{4} x^{4}+a_{5} x^{5}\right) \\
=\tau\left(1+x+2 x^{2}+5 x^{3}+14 x^{4}+42 x^{5}\right)
\end{gathered}
$$

At $x=0, y_{5}(0)=1$ so that from (5.2a),

$$
a_{0}=1
$$

From (4.2), the collocation points are

$$
x=\frac{1}{6}, \frac{2}{6}, \frac{3}{6}, \frac{4}{6}, \frac{5}{6}
$$

Collocating (5.5) at the points in (5.7) couple with equations (5.6) we obtain the following system of equations $A x=b$

where

$$
A=\left[\begin{array}{cccccc}
\frac{215}{216} & \frac{431}{1296} & \frac{647}{7776} & \frac{863}{46656} & \frac{1079}{279936} & -\frac{545}{432} \\
\frac{26}{27} & \frac{53}{81} & \frac{80}{243} & \frac{107}{729} & \frac{134}{2187} & -\frac{169}{81} \\
\frac{7}{8} & \frac{15}{16} & \frac{23}{32} & \frac{31}{64} & \frac{39}{128} & -\frac{77}{16} \\
\frac{19}{27} & \frac{92}{81} & \frac{292}{243} & \frac{800}{729} & \frac{2032}{2187} & -\frac{37}{3} \\
\frac{91}{216} & \frac{1535}{1296} & \frac{13075}{7776} & \frac{92375}{46656} & \frac{596875}{279936} & -\frac{38551}{1296} \\
0 & 1 & 2 & 3 & 4 & -65
\end{array}\right]
$$

$\mathbf{x}=\left[a_{1}, a_{2}, a_{3}, a_{4}, a_{5}, \tau\right]$ and $\mathbf{b}=\left[\frac{1}{36}, \frac{1}{9}, \frac{1}{4}, \frac{4}{9}, \frac{25}{36}, 1\right]$

which can be solved using Gaussian elimination for the 6 unknowns. The dimension of $A$ is determined by the degree of Catalan polynomial used. These obtained values of $a$, are substituted in (5.2a) to obtain the required approximate solution. The error is defined as

$$
\text { Error }=\left|y_{\text {exact }}-y_{i}\right|
$$

and are shown for example 1 in table 1, column 2.

Example 2: $y^{\prime}(x)-y(x)=x, \quad 0 \leq x \leq 1, y(0)=0, \quad y_{\text {exact }}(x)=e^{x}-1-x$

The calculation is carried out as in example 1 above. The errors are shown in table 1 , colurnn 4 . 
Example 3: $2(1+x) y^{\prime}+y=0, \quad 0 \leq x \leq 1, \quad y(0)=1, \quad y_{\text {exact }}=\frac{1}{\sqrt{(1+x)}}$

Again, we follow the calculations as in example 1. The errors are shown in table 2, column 2.

Example 4: $y^{\prime \prime}(x)-y(x)=0,0 \leqslant x \leqslant 1, y(0)=1, y(1)=3, \quad \gamma_{\text {axsac }}(x)=\frac{\operatorname{sinhx}}{\operatorname{sinhilose}}$

We assume using (5.2a) an approximate power series solution of the form:

so that

$$
y_{i}(x)=\sum_{j=0}^{i} a_{j} x^{j}
$$

$$
\left.y_{i}^{\prime}(x)=\sum_{j=0}^{1} j a_{i} x^{j-1}, \quad y_{i}^{\prime \prime}(x)=\sum_{j=0}^{i} j i j-1\right) a_{i} x^{i \cdot 2}
$$

Equation (5.2a) is then substituted in the slightly perturbed form of equation (5.9) to obtain

$$
y_{i}^{\prime \prime}(x)-y_{i}(x)=\pi C_{i}(x)
$$

Substitute (5.2a) and (5.10) in (5.11) to obtain

$$
\begin{gathered}
\left(2 a_{2}+6 a_{3} x+12 a_{4} x^{2}+20 a_{5} x^{3}\right)-\left(a_{0}+a_{1} x+a_{2} x^{2}+a_{3} x^{3}+a_{4} x^{4}+a_{5} x^{5}\right) \\
=\tau\left(1+\mathrm{x}+2 \mathrm{x}^{2}+5 x^{3}+14 x^{4}+42 x^{5}\right)
\end{gathered}
$$

At $x=0, y_{5}(0)=1$ so that from (5.2a),

$$
a_{0}=1
$$

At $x=1, y_{5}(1)=3$ so that from $(5.2 a)$,

$$
a_{0}+a_{1}+a_{2}+a_{3}+a_{4}+a_{5}=3
$$

- That is,

$$
a_{1}+a_{2}+a_{3}+a_{4}+a_{5}=2
$$

since $a_{0}=1$.

Collocating (5.12) at the points in (5.7) together with equations (5.13) we obtain the following system of equations $A x=b$

where

$$
\begin{aligned}
A & =\left[\begin{array}{cccccc}
1 & 1 & 1 & 1 & 1 & 0 \\
-1296 & 15336 & 7740 & 2586 & 719 & -7776 \\
-2592 & 14688 & 15264 & 10272 & 5728 & -16224 \\
-3888 & 13608 & 22356 & 22842 & 19197 & -37422 \\
-5184 & 12096 & 28800 & 39936 & 45056 & -95904 \\
-6480 & 10152 & 34380 & 61050 & 86875 & -231306
\end{array}\right] \\
\mathbf{x} & =\left[a_{1}, a_{2}, a_{3}, a_{4}, a_{5}, \tau\right]^{\gamma} \text { and } \mathbf{b}=[2,7776,7776,7776,7776,7776]^{r}
\end{aligned}
$$

which can be solved using Gaussian elimination for the 6 unknowns. These values of $a_{i}$ are substituted in (5.2a) to obtain the required approximate solution. The values of the errors for different values of $x$ are shown in table 5.4.

Example 5: $y^{\prime \prime}(x)-2\left(1+2 x^{2}\right) y(x)=0, \quad 0 \leq \mathrm{x} \leq 1, \quad \mathrm{y}(0)=1, \mathrm{y}^{\prime}(0)=0 \quad \mathrm{y}_{\mathrm{exact}}(x)=e^{x^{2}}$ In this case, equation (5.5) becomes

$$
\begin{gathered}
\left(2 a_{2}+6 a_{3} x+12 a_{4} x^{2}+20 a_{5} x^{3}\right)-2\left(1+2 x^{2}\right)\left(a_{0}+a_{1} x+a_{2} x^{2}+a_{3} x^{3}+a_{4} x^{4}+a_{5} x^{5}\right) \\
=\tau\left(1+\mathrm{x}+2 \mathrm{x}^{2}+5 x^{3}+14 x^{4}+42 x^{5}\right)
\end{gathered}
$$

Following the steps in the solution of example 1, we obtain the results for the errors as shown in table 2. column 4.

\section{0}

\section{PRESENTATION OF RESULTS}

Omolehin (1997) claimed that his method not only compared favorably with other collocation methods (e.g: Okunuga and Onumanyi, 1986; Taiwo and Onumanyi, 1990, Lanczos, 1956), it is even more powertul than any other method therefore, it will be reasonable to cobmpare our result with his. In arriving at these reported results, we have subjected the two methods to "rough numerical procedures". For examples, single precision and low degree polynomials (in this case 5) were used. 
Table 1: The errors as defined by (5.8) for examples 1 and 2

\begin{tabular}{|l|l|l|l|l|}
\hline \multirow{3}{*}{$x$} & \multicolumn{3}{|l|}{$\begin{array}{l}\text { Example 1 } \\
y^{\prime}(x)-x^{2} y(x)=0\end{array}$} & $\begin{array}{l}\text { Example 2 } \\
y^{\prime}(x)-y(x)=x\end{array}$ \\
\cline { 2 - 5 } & New Method & Omolehin $(1997)$ & New Method & Omolehin (1997) \\
\hline 0.0 & $0.000000 \mathrm{E}-00$ & $0.000000 \mathrm{E}-00$ & $0.000000 \mathrm{E}-00$ & $0.000000 \mathrm{E}-00$ \\
\hline 0.1 & $6.395450 \mathrm{E}-04$ & $2.547870 \mathrm{E}-03$ & $2.054500 \mathrm{E}-05$ & $1.006480 \mathrm{E}-04$ \\
\hline 0.2 & $1.400241 \mathrm{E}-03$ & $5.501073 \mathrm{E}-03$ & $4.654200 \mathrm{E}-05$ & $2.265260 \mathrm{E}-04$ \\
\hline 0.3 & $2.379263 \mathrm{E}-03$ & $9.085706 \mathrm{E}-03$ & $8.174600 \mathrm{E}-05$ & $3.887540 \mathrm{E}-04$ \\
\hline 0.4 & $3.820331 \mathrm{E}-03$ & $1.372529 \mathrm{E}-02$ & $1.342920 \mathrm{E}-04$ & $6.053390 \mathrm{E}-04$ \\
\hline 0.5 & $6.216569 \mathrm{E}-03$ & $2.013859 \mathrm{E}-02$ & $2.202550 \mathrm{E}-04$ & $9.065070 \mathrm{E}-04$ \\
\hline 0.6 & $1.046565 \mathrm{E}-02$ & $2.948974 \mathrm{E}-02$ & $3.685560 \mathrm{E}-04$ & $1.337930 \mathrm{E}-03$ \\
\hline 0.7 & $1.809325 \mathrm{E}-02$ & $4.360661 \mathrm{E}-02$ & $6.273670 \mathrm{E}-04$ & $1.970044 \mathrm{E}-03$ \\
\hline 0.8 & $3.157353 \mathrm{E}-02$ & $6.529626 \mathrm{E}-02$ & $1.072162 \mathrm{E}-03$ & $2.905566 \mathrm{E}-03$ \\
\hline 0.9 & $5.479499 \mathrm{E}-02$ & $9.880582 \mathrm{E}-02$ & $1.815605 \mathrm{E}-03$ & $4.290231 \mathrm{E}-03$ \\
\hline 1.0 & $9.375282 \mathrm{E}-02$ & $1.505097 \mathrm{E}-01$ & $3.019448 \mathrm{E}-03$ & $6.325306 \mathrm{E}-03$ \\
\hline
\end{tabular}

Table 2: The errors as defined by (5.8) for examples 3 and 4 .

\begin{tabular}{|l|l|l|l|l|}
\hline \multirow{3}{*}{$x$} & \multicolumn{3}{|l|}{$\begin{array}{l}\text { Example 3 } \\
2(1+x) y^{\prime}+y=0\end{array}$} & \multicolumn{2}{l|}{$\begin{array}{l}\text { Example 4 } \\
y^{\prime \prime}(x)-2\left(1+2 x^{2}\right) y(x)=0\end{array}$} \\
\cline { 2 - 6 } & New Method & Omolehin (1997) & New Method & Omolehin (1997) \\
\hline 0.0 & $0.000000000 \mathrm{E}-00$ & $0.000000000 \mathrm{E}-00$ & $0.000000 \mathrm{E}-00$ & $0.000000 \mathrm{E}-00$ \\
\hline 0.1 & $4.595393000 \mathrm{E}-03$ & $4.432293000 \mathrm{E}-02$ & $5.052300 \mathrm{E}-04$ & $1.862501 \mathrm{E}-03$ \\
\hline 0.2 & $9.278979400 \mathrm{E}-03$ & $8.429822250 \mathrm{E}-02$ & $2.170922 \mathrm{E}-03$ & $7.848537 \mathrm{E}-03$ \\
\hline 0.3 & $1.463548800 \mathrm{E}-02$ & $1.228968966 \mathrm{E}-01$ & $5.309428 \mathrm{E}-03$ & $1.881729 \mathrm{E}-02$ \\
\hline 0.4 & $2.180051370 \mathrm{E}-02$ & $1.162682975 \mathrm{E}-01$ & $1.051579 \mathrm{E}-02$ & $3.618571 \mathrm{E}-02$ \\
\hline 0.5 & $3.279740030 \mathrm{E}-02$ & $2.059117318 \mathrm{E}-01$ & $1.901425 \mathrm{E}-02$ & $6.232871 \mathrm{E}-02$ \\
\hline 0.6 & $5.090588630 \mathrm{E}-02$ & $2.545961909 \mathrm{E}-01$ & $30321964 \mathrm{E}-02$ & $1.011944 \mathrm{E}-01$ \\
\hline 0.7 & $8.105018170 \mathrm{E}-02$ & $3.105541711 \mathrm{E}-01$ & $5.760021 \mathrm{E}-02$ & $1.592223 \mathrm{E}-01$ \\
\hline 0.8 & $1.301993363 \mathrm{E}-01$ & $3.754430638 \mathrm{E}-01$ & $9.999662 \mathrm{E}-02$ & $2.467071 \mathrm{E}-01$ \\
\hline 0.9 & $2.077756467 \mathrm{E}-01$ & $4.507865548 \mathrm{E}-01$ & $1.735800 \mathrm{E}-01$ & $3.798287 \mathrm{E}-01$ \\
\hline 1.0 & $3.260684430 \mathrm{E}-01$ & $5.379959790 \mathrm{E}-01$ & $2.998707 \mathrm{E}-01$ & $5.837067 \mathrm{E}-01$ \\
\hline
\end{tabular}

Table 3: The errors as defined by (5.8) for example 5.

\begin{tabular}{|l|l|l|}
\hline \multirow{3}{*}{$x$} & $\begin{array}{l}\text { Example 5 } \\
y \prime(x)-y(x)=0\end{array}$ \\
\cline { 2 - 3 } & New Method & Omolehin (1997) \\
\hline 0.0 & $0.00000 \mathrm{E}-00$ & $0.00000 \mathrm{E}-00$ \\
\hline 0.1 & $1.40860 \mathrm{E}-04$ & $3.13123 \mathrm{E}-04$ \\
\hline 0.2 & $2.78891 \mathrm{E}-04$ & $5.98206 \mathrm{E}-04$ \\
\hline 0.3 & $4.11885 \mathrm{E}-04$ & $8.53161 \mathrm{E}-04$ \\
\hline 0.4 & $5.36841 \mathrm{E}-04$ & $1.07200 \mathrm{E}-03$ \\
\hline 0.5 & $6.47882 \mathrm{E}-04$ & $1.24294 \mathrm{E}-03$ \\
\hline 0.6 & $7.32695 \mathrm{E}-04$ & $1.34506 \mathrm{E}-03$ \\
\hline 0.7 & $7.67428 \mathrm{E}-04$ & $1.34339 \mathrm{E}-03$ \\
\hline 0.8 & $7.09747 \mathrm{E}-04$ & $1.18217 \mathrm{E}-03$ \\
\hline 0.9 & $4.89977 \mathrm{E}-04$ & $7.76220 \mathrm{E}-04$ \\
\hline 1.0 & $1.00000 \mathrm{E}-09$ & $1.00000 \mathrm{E}-09$ \\
\hline
\end{tabular}

\section{SUMMARY AND CONCLUSION}

From the results obtained as shown in tables 1-3, the new collocation approach compared favorably with Omolehin (1997)and hence with any other collocation methods (Omolehin, 1997). "The use of multiple $\tau$ is eliminated (Lanczos, 1956) making the calculation faster due to reduction in the size of the matrix system to be snived. This gives our approach an edge over these other previous methods just like Omolehin's method with the same computational effort as his. The choice of Catalan polynomials as our perturbation polynomiais is very economical because it is very easy to compute when compared with the computations of shifted Chebyshev polynomials used in most of these 
previously (Okunuga and Onumanyi, 1986; Taiwo and Onumanyi, 1990) mentioned methods. The fast rate of Catalan constants (Sloane, A006752/M4593; Weisstein, 1999) is made use of here to give us an edge over Omolehin's work. This is an attempt to introduce the use of Catalan polynomials into the numerical solution of differential equations directly and the result is ver encouraging.

As expected, it is worth mentiuning that the method does not behave so well with stiff problems.

\section{REFERENCES}

Clenshaw, C.W., 1962. Chebyshev series for mathematical functions, National Physical Laboratory Mathematical Tables 5, A. M. S. O., London.

Lanczos, C., 1938. Trigonometric interpolation of empirical and analytic functions, J. Math. Phys. 17: 123 - 199.

Lanczos, C., 1952. Tables of Chebyshev polynomials, National Bureau of Standards, Applied Math. Series 9. Government printing office, Washington.

Lanczos, C., 1956. Applied Analysis, Prentice Hall, New Jersey.

Odekunle, M. R., 1993. Solution of Boundary Value Problems by Lanczos - Chebyshev Method with an Error Estimation. M.Sc. Dissertation, University of llorin, Ilorin, Nigeria. \

Okunuga, S. A. and Onumanyi, P., 1986. A collocation tau method for the solution of odes, Abacus, Journal of Mathematical Association of Nigeria, 17(1): 51 - 60 .

Omolehin, J.O., 1997. Fibonacii approach to collocation tau method for ordinary differential equations. Abacus, Journal of Mathematical Association of Nigeria, 25(2): 381 - 391.

Parker, S.P. (ed. in chief), 1984. McGraw-hill concise encyclopedia of science and technology, McGraw-hill Inc., USA.

Sloane, N.J.A. Sequences A006752/M4593 in The On-line encyclopedia of integer sequences. http://umw.research. att.com/ njas/sequences/. Downloaded on $15^{\text {th }}$ of January, 2005.

Srivastava, H. M. and Miller, E. A., 1990. A simple reducible case of double hypergeometric series involving Catalan's constant and Riemann's zeta function. Int. J. Math. Educ. Sci. Technol. 21: 375 - 377.

Taiwo, A.O. and Onumanyi, P., 1990. A collocation approximation of singularly perturbed second order ordinary differential equation. Inter. J. Computer math., 39: 205 - 211.

Woisstein, E.W., 1999. Catalan Constants. Wolfram Research, Inc. CRC Press LL.C. 